Published in final edited form as:

Am J Ind Med. 2015 January ; 58(1): 14-20. doi:10.1002/ajim.22389.

\title{
Occupational Exposures and Longitudinal Lung Function Decline
}

\author{
Shu-Yi Liao, MD, MPH, MS, ScD ${ }^{1}$, Xihong Lin, $\mathrm{PhD}^{1}$, and David C. Christiani, MD, MPH, \\ MS $^{1,2}$ \\ ${ }^{1}$ Harvard School of Public Health, Boston, Massachusetts \\ ${ }^{2}$ Harvard Medical School, Boston, Massachusetts
}

\begin{abstract}
Background-Few longitudinal studies have been conducted on occupational exposure and lung function. This study investigated occupational dust exposure effects on lung function and whether genetic variants influence such effects.

Methods-The study population (1,332 participants) was from the Framingham Heart Study, in which participant lung function measures were available from up to five examinations over nearly 17 years. Occupational dust exposures were classified into "more" and "less" likely dust exposure. We used linear mixed effects models for the analysis.

Results-Participants with more likely dust exposure had a mean $4.5 \mathrm{~mL} /$ year excess loss rate of $\mathrm{FEV}_{1}$ over time. However, occupational dust exposures alone or interactions with age or time had no significant effect on $\mathrm{FEV}_{1} / \mathrm{FVC}$. No statistically significant effects of genetic modifications in the different subgroups were identified for $\mathrm{FEV}_{1}$ loss.
\end{abstract}

Conclusions-Occupational dust exposures may accelerate the rate of $\mathrm{FEV}_{1}$ loss but not $\mathrm{FEV}_{1} / \mathrm{FVC}$ loss.

\section{Keywords}

job exposure matrix; forced expiratory volume in one second; chronic obstructive pulmonary disease; environmental lung disease; environmental health; occupational health; occupational respiratory disease

\section{Introduction}

Chronic obstructive pulmonary disease (COPD) affects between $6 \%$ and $20 \%$ of people worldwide [Buist et al., 2008]. Diagnosis of COPD usually employs a measure of the forced expiratory volume in one second $\left(\mathrm{FEV}_{1}\right)$ and ratio of $\mathrm{FEV}_{1}$ to forced vital capacity $(\mathrm{FVC})$. $\mathrm{FEV}_{1}$ is a stable measure of lung function and has been shown to predict clinical outcome, as well to reflect the severity and natural history of obstructive lung disease. Smoking is a

*Correspondence to: David C. Christiani, MD, MPH, MS, 665 Huntington Avenue Building I Room 1401 Boston, Massachusetts 02115.dchris@hsph.harvard.edu.

Disclosure Statement: The authors report no conflicts of interests. 
well-known important risk factor for COPD. However, in the United States, 15\% to 20\% of COPD cases are attributable to occupational exposure [Balmes et al., 2003].

Occupational exposure to dust has been associated with COPD or poor lung function in both industry-based [Higgins, 1973; Kauffmann et al., 1982; Oxman et al., 1993; Johnsen et al., 2008] and community-based [Korn et al., 1987; Krzyzanowski and Kauffmann, 1988; Bakke et al., 1991; Viegi et al., 1991; Heederik et al., 1992] cross-sectional studies, although some results are controversial [Petran et al., 2000]. Industry-based longitudinal studies have shown that occupational exposure is associated with accelerated lung function decline in the furniture industry [Jacobsen et al., 2008], in blue-collar workers [Thaon et al., 2012], in smelters [Johnsen et al., 2010], and in flavoring manufacturing workers [Kanwal et al., 2011; Kreiss et al., 2011]. Other longitudinal studies have shown that lung function declines in occupational settings [Wang and Petsonk, 2004; Wang et al., 2006; Hnizdo et al., 2010].

Few community-based studies have been published based on longitudinal pulmonary function data; importantly, the follow-up times were short ( $<10$ years), and the numbers of repeated measurements were few (only two or three repeated measurements) for those studies. A recent review of occupational chronic obstructive pulmonary diseases summarized the results of the lung function/COPD studies using either industry-specific or population-based data [Omland et al., 2014].

A community-based longitudinal study offers several advantages. For example, studies in industry-based populations tend to focus on workers who are less susceptible participants, such as blue-collar workers who are usually healthier or stronger than the general population and thus more prone to healthy worker effect bias. Community-based studies, however, can provide more generalizable information since they include participants from many different industries. Additionally, in contrast to cross-sectional studies, longitudinal studies can help characterize aging and normal development as well as improvement or decline in lung function, to distinguish the effects of time. Longitudinal studies also allow for consideration of time-dependent variables such as change in smoking status between different examinations.

The pathophysiological mechanisms of all cause (e.g., aging and cigarette smoking) accelerated decline of $\mathrm{FEV}_{1}$ are thought to be multifactorial, involving genetic factors, cellular repair, and inflammatory response and resolution [MacNee and Tuder, 2009]. Genes and environmental interaction such as occupational exposure may thus interact with each other and affect the lung function. In a previous gene-environmental interaction study on cross-sectional lung function, we found a single nuclear polymorphism, rs9931086, in the gene SLC $38 A 8$ on chromosome 16, that significantly modified the association of occupational dust exposure with cross-sectional $\mathrm{FEV}_{1}$, and another single nuclear polymorphism, rs 17051547, on chromosome 4, that modified the association of occupational dust exposure with cross-sectional $\mathrm{FEV}_{1} / \mathrm{FVC}$ (using the SNP with the smallest $p$ value which did not, however, reach genome-wide significance) [Liao et al., 2013].

In this study, we stratified our participants into two genetic groups and assessed whether the single nucleotide polymorphisms rs 9931086 or rs17051547 also modified the association of 
occupational dust exposure with longitudinal lung function. The purpose of the study was to determine how occupational dust exposures affect lung function change over time and whether genetic variants influence occupational dust exposure effects on lung function change over time in a longitudinal community-based study population with an average of 17 years of follow-up.

\section{Materials and Methods}

\section{Study Population}

Our study used the Framingham Heart Study (FHS) population, which includes mainly Whites who live in Framingham, Massachusetts, USA. Manufacturing, such as automobile production, had been a key economic feature of Framingham at the time of the first generation study, but in the past 3-4 decades, as in other United States industrial towns, manufacturing left and now Framingham is a retail center for the region. The FHS has recruited participants since 1948, and participants have returned approximately every two years for spirometry measurement, detailed medical history, physical examination, and laboratory tests. Three generations have participated in the FHS: the original cohort, their offspring, and the third generation. Here, we used the offspring cohort, which has available longitudinal lung function measurements. The study population comprises participants with at least one spirometry measurement, current occupation information, and covariates. A total of 1,332 participants (261 families and 352 individuals without relatives) with 4,734 observations were used for our longitudinal analysis.

\section{Ethics Statement}

Written informed consent was provided by all participants. Protocols were approved by local institutional review boards.

\section{Spirometry Phenotypes, Covariates, and Genotypings}

Spirometry data from participants having acceptable pulmonary function were used in our study. Accessible examinations were obtained from Offspring Exams 3, 5, 6, 7, and 8. FEV 1 and $\mathrm{FEV}_{1} / \mathrm{FVC}$ values were used as continuous outcomes. Gender and baseline age were time-independent variables; height (inches), pack-years, years after baseline, and smoking status at the time of each examination were time-dependent variables and were used as covariates in our analysis. Smoking status (never, former, and current smokers) was coded as a dummy variable. The genotyping was conducted with Affymetrix $500 \mathrm{~K}$ mapping plus Affymetrix $50 \mathrm{~K}$ supplemental array. The method has been described in detail in our previous study [Liao et al., 2013].

\section{Occupational Dust Exposure}

Although the lung function was measured longitudinally (exams $3,5,6,7,8$ ), the occupation information was only measured at exam 8 . We did not have information on how long participants remained on the job or whether their occupations changed during the follow-up period. We excluded participants who retired or reported their jobs as unknown or other (retired, other, and unknown are three separate categories). For occupational dust exposure classification, we used a mini population-specific job exposure matrix (JEM) (Table I) [Liao 
et al., 2013] modified from the UCSF COPD Job Exposure Matrix (January, 2009 revision) [Blanc et al., 2009] for occupational exposure (with job category codes rather than specific occupational codes in the UCSF COPD JEM). Occupational dust exposure was classified as "more likely dust exposure" for job categories (factory/assembly/mechanic, skilled labor, general labor, and heavy labor) that were classified as high exposure in the UCSF COPD Job Exposure Matrix. Occupational dust exposure was classified as "less likely dust exposure" for homemakers and the remaining job categories. There were 29 job categories in the FHS occupations classification, which were less detailed than the UCSF COPD Job Exposure Matrix. For example, in the FHS occupational classification, the category of skilled labor (classified as more likely dust exposure) included some jobs (e.g., plumber, carpenter, and painter) classified as job with dust exposure and some jobs (e.g., hairdresser) classified as no dust exposure in the UCSF COPD Job Exposure Matrix.

\section{Statistical Analysis}

For longitudinal analysis we used a linear mixed effects model for the association between $\mathrm{FEV}_{1}$ or $\mathrm{FEV}_{1} / \mathrm{FVC}$ and dust exposure groups, adjustment for relevant covariates. Random effects were used to account for the correlation between repeated measures within each subject and the correlation among observations from multiple individuals within a family. Specifically, we used a family random intercept to account for the correlation of the measures of different individuals within the same family, and individual random intercept/ random age slope to account for correlation of repeated measures over time within the same individual. In addition to main effects, we also included two interaction terms, dust exposure (E) and baseline age (centered by mean baseline age for whole the population, Age$\mathrm{Age}_{\text {mean }}$ ) and years after baseline in which the lung function was measured (T). These two interaction terms are presented as $E_{i j} *\left(A g e-A g e_{\text {mean }}\right)_{i j}$ and $E_{i j} * T_{i j t}$ below. $Y_{i j t}$ denotes the outcome $\left(\mathrm{FEV}_{1}\right.$ or $\left.\mathrm{FEV}_{1} / \mathrm{FVC}\right)$ for subject $j$ of family $i$ measured at year $t$. The mixed effects model can be written as below:

$Y_{i j t}=\beta_{0}+\beta_{1}^{*} E_{i j}+\beta_{2}^{*}\left(A g e-A g e_{m e a n}\right)_{i j}+\beta_{3}^{*} T_{i j t}+\beta_{4}^{*} E_{i j}^{*}\left(A g e-A g e_{m e a n}\right)_{i j}+\beta_{5}^{*} E_{i j}^{*} T_{i j t}+a X_{i j t}+b_{i}+a_{i j}+c_{i j} T_{i j t}+e_{i j k}$,

where the $X_{i j t}$ are other covariates at year $t$, the $b_{i}$ are family random effects, the $a_{i j}$ and $c_{i j}$ are subject-specific random intercept and slopes and $e_{i j k}$ are residuals. Analyses were performed using SAS PROC MIXED (version 9.2; SAS Institute Inc., Cary, NC).

We stratified our participants into subgroups based on the genotype of the single nucleotide polymorphisms rs 9931086 and rs17051547 that we previously identified as potential interacting variants for occupational exposure and lung function [Liao et al., 2013]. For analysis of the genetic modification of rs9931086, one subgroup comprised participants with one or two $\mathrm{C}$ alleles on rs9931086 (AC/CC), and the other subgroup comprised participants without a $\mathrm{C}$ allele (AA). For analysis of the genetic modification of rs17051547, one subgroup comprised participants with one or two A alleles on rs17051547 (AC/AA), and the other subgroup comprised participants without an A allele (CC). We analyzed the data separately and compared the effect of occupational dust exposures in these subgroups. We 
also tested the difference of the effects in these subgroups using three way interaction analyses with the model written as below:

$$
\begin{aligned}
Y_{i j t} & =\beta_{0}+\beta_{1}^{*} E_{i j}+\beta_{2}^{*}\left(\text { Age }- \text { Age } e_{\text {mean }}\right)_{i j} \\
& +\beta_{3}^{*} T_{i j t}+\beta_{4}^{*} E_{i j}^{*}\left(\text { Age }- \text { Age } e_{\text {mean }}\right)_{i j} \\
& +\beta_{5}^{*} E_{i j}^{*} T_{i j t} \\
& +\beta_{6}^{*} G_{\text {group }}+\beta_{7}^{*} G_{\text {group }}^{*} T_{i j t} \\
& +\beta_{8}^{*} G_{\text {group }}^{*} E_{i j} \\
& +\beta_{9}^{*} G_{\text {group }}^{*} E_{i j}^{*} T_{i j t} \\
& +a X_{i j t}+b_{i}+a_{i j}+c_{i j} T_{i j t}+e_{i j k},
\end{aligned}
$$

where $\mathrm{G}_{\text {group }}$ are coded as 1 and 0 to represent the two subgroups and tested for $\beta_{9}$.

\section{Results}

There were 1,332 participants with an average of 3.55 (median $=4$ ) repeated lung function measurements/per person. Among them, 1,188 participants were in the less likely dust exposure group, with an average of 3.58 (median $=4$ ) repeated measurements/per person, and 144 participants were in the more likely dust exposure group with an average of 3.38 $($ median $=4)$ repeated measurements/per person.

Table II summarizes the baseline characteristics for groups with different dust exposure likelihood at final follow-up (Exam 8). The mean follow-up time was about 17 years in both groups. At baseline, $\mathrm{FEV}_{1}$ was higher in the group with more likely dust exposure, but the $\mathrm{FEV}_{1} / \mathrm{FVC}$ ratio was the same for both groups. Additionally, the prevalence of current and former smokers at baseline was higher in the group with more likely dust exposure.

Table III shows the results of the linear mixed model fit of $\mathrm{FEV}_{1}$ and $\mathrm{FEV}_{1} / \mathrm{FVC}$ on centered baseline age, years after baseline, centered baseline age by dust exposure interaction, and years after baseline by dust interaction, adjusting for covariates. The association of dust exposure as a main effect on $\mathrm{FEV}_{1}$ was not significant at baseline for subjects with a mean age of 47.44 years old. The decrement in $\mathrm{FEV}_{1}$ associated with a oneyear increase in the baseline age (cross-sectional age effect) for the less likely dust exposure group was $-30.6 \pm 1.3 \mathrm{~mL} /$ year, adjusted by gender, height, smoking, and pack-years at baseline $(P$-value $<0.0001)$. Some evidence indicated different cross-sectional age effects between the two dust exposure groups $(P$-value $=0.05)$, with a bigger mean difference between the two dust exposure groups for older subjects.

The $\mathrm{FEV}_{1}$ annual loss rate (longitudinal time effect) for the less likely dust exposure group was $-25.8 \pm 0.6 \mathrm{~mL} /$ year adjusted by other covariates $(P$-value $<0.0001)$. Subjects with more likely dust exposure had a statistically significant $4.5 \pm 1.7 \mathrm{~mL} / \mathrm{year}$ mean excess loss of $\mathrm{FEV}_{1}$ over time compared to those with less likely dust exposure $(P$-value $=0.0074)$. No significant effect of occupational dust exposure was observed on the $\mathrm{FEV}_{1} / \mathrm{FVC}$ ratio. 
As expected, males had a significantly higher $(712.6 \pm 34.1 \mathrm{~mL})$ mean $\mathrm{FEV}_{1}$ than females. Current smokers $(-135.9 \pm 22.4 \mathrm{~mL})$ and former smokers $(-92.8 \pm 19.6 \mathrm{~mL})$ had a significantly lower mean $\mathrm{FEV}_{1}$ than never smokers. Each increase in pack-years significantly decreased the mean $\mathrm{FEV}_{1}$ by $2.8 \pm 0.4 \mathrm{~mL}$. For each one-inch increase in height, the $\mathrm{FEV}_{1}$ significantly increased by $61.5 \pm 4.2 \mathrm{~mL}$.

Comparing the two subgroups stratified by genotype of rs9931086, there was a mean 6.5 $\pm 3.4 \mathrm{~mL} /$ year mean excess loss of $\mathrm{FEV}_{1}$ over time $(P=0.05)$ among those with more likely dust exposure compared to those with less likely dust exposure in the AC/CC group (at least one $\mathrm{C}$ allele in rs9931086) and a $3.8 \pm 2.1 \mathrm{~mL} /$ year mean excess loss of $\mathrm{FEV}_{1}$ over time $(P=$ 0.07) in the AA group (no $\mathrm{C}$ allele in rs9931086). However, the difference in $\mathrm{FEV}_{1}$ loss across dust exposure strata was not significant across the two genotype subgroups $(P=0.53$ in the three way interaction analysis). No significant effect of occupational dust exposure was observed on the $\mathrm{FEV}_{1} / \mathrm{FVC}$ ratio loss in either the $\mathrm{CC}(P=0.19)$ or the AA/AC group $(P=0.42)$ stratified by genotype of rs 17051547 although the difference in $\mathrm{FEV}_{1} / \mathrm{FVC}$ loss across dust exposure strata was significant across the two genotype subgroups $(P=0.03$ in the three way interaction analysis).

Figure 1 demonstrates different annual $\mathrm{FEV}_{1}$ loss for a male who was 67 inches tall across the different dust exposure groups, baseline age, and pack-years. The more likely dust exposure group had a larger $\mathrm{FEV}_{1}$ annual loss. Compared to former smokers with 20 packyears smoking history but no dust exposure, former smokers with dust exposure had greater loss in $\mathrm{FEV}_{1}$ after 8 to 9 years, even with 10 pack-years less smoking history. The effect of occupational dust exposure on the $\mathrm{FEV}_{1}$ annual loss $(4.5 \mathrm{~mL} / \mathrm{year})$ was greater than the effect of each pack-year ( $2.8 \mathrm{~mL}$ ). For older participants (e.g., baseline age of 60 years old), the mean difference between different dust exposure groups was larger than for younger participants.

\section{Discussion}

We found that occupational dust exposure was not associated with cross-sectional $\mathrm{FEV}_{1}$ cross-sectional $\mathrm{FEV}_{1} / \mathrm{FVC}$, or longitudinal $\mathrm{FEV}_{1} / \mathrm{FVC}$ annual loss in a general population study. However, we did find dust associated accelerated longitudinal $\mathrm{FEV}_{1}$ annual loss, and this effect was greater than the effect of each pack-year increase. Dust exposure also modified the effect of age at baseline on cross-sectional $\mathrm{FEV}_{1}$.

We distinguished the age effect as two components: cross-sectional age effect and longitudinal time effect. In our model, the coefficient of baseline age represents the crosssectional age effect, and the coefficient of years after baseline represents the longitudinal time effect. For the cross-sectional age effect, we found that, for participants at baseline, each year of age decreased the $\mathrm{FEV}_{1}$ significantly when other covariates remained constant. This effect was modified by dust exposure. For example, at baseline, the difference between each male non-smoker of 67-inch height and a matched male one year older was greater in the group with dust exposure. The difference between different exposure groups was higher in older subjects. 
For the longitudinal time effect, we found that participants having the same baseline age had significant annual $\mathrm{FEV}_{1}$ loss, but the annual loss were higher in participants in the more likely dust exposure group. This result implies that, in populations similar to the Framingham Offspring Cohort, occupational dust exposure may not affect $\mathrm{FEV}_{1}$ (occupational dust exposure is not significantly associated with lower average $\mathrm{FEV}_{1}$ in this population), but may accelerate $\mathrm{FEV}_{1}$ loss. The effect of dust exposure $(4.5 \mathrm{~mL} / \mathrm{year}$ excess loss) is greater than the loss caused by each pack-year increase in smoking $(2.8 \mathrm{~mL})$. This accelerated $\mathrm{FEV}_{1}$ annual loss rate is consistent with a previous study [Johnsen et al., 2010]. Estimates of moderate to heavy smoking in a review of $\mathrm{FEV}_{1}$ decline by age and smoking show a mean excess loss of $15 \mathrm{~mL} /$ year compared to non-smokers [Kerstjens et al., 1997]. The mean excess loss of $\mathrm{FEV}_{1}$ attributable to occupational dust exposure in our study is about $1 / 3$ of that due to smoking and therefore can be clinically significant over a lifetime. The absence of an overall effect of dust exposure on $\mathrm{FEV}_{1}$ is also consistent with some previous studies [Petran et al., 2000; Zock et al., 2001].

The non-significant occupational dust exposure main effect may result from population selection. For our studies, occupational information was only available at exam 8 (the latest exam). Therefore, our participants were assumed to be active workers at exam 8 .

Participants without occupational information included retired individuals. This could skew selection toward healthier workers, especially in the job categories that require heavy labor (e.g., workers with respiratory diseases might not enter high-exposure jobs or might leave these jobs before the end of the study), causing a healthy worker effect confounding bias [Monson, 1990; Eisen et al., 1995; Li and Sung, 1999]. Since heavy labor job categories were classified as more likely for dust exposure, and if we assume that participants in the group were those in better health, then the magnitude of dust exposure's effect on $\mathrm{FEV}_{1}$ is an underestimate. In addition, a healthy smoker effect confounding bias [Becklake and Lalloo, 1990] may explain why mean $\mathrm{FEV}_{1}$ was higher in the more likely exposure group despite a higher prevalence of smoking.

However, even though these participants might be healthier, their $\mathrm{FEV}_{1}$ loss rates were a significant $4.5 \mathrm{~mL} /$ year higher than participants in the less likely dust exposure group. Our observed accelerated loss is lower than a previous study that reported an excess loss in FEV 1 of 5.7 to $6.4 \mathrm{~mL} /$ year, although that study was industry-based [Johnsen et al., 2010]. One study of blue-collar workers exposed to welding fumes concluded that the absence of a significant effect of occupational dust exposure on lung function in smokers was because of a healthy worker effect [Thaon et al., 2012], but we did not find a significant joint effect (interaction) of tobacco use and occupational dust exposure (data not shown). Genetic factors may also play an important role in the lung function through interactions with occupational dust exposure, but we did not find a significant effect of genetic modifications on $\mathrm{FEV}_{1}$ or $\mathrm{FEV}_{1} / \mathrm{FVC}$ loss.

Even though our results have merit in offering insights into the effects of occupational dust exposures on lung function loss in a community-based study, we acknowledge some limitations. One limitation concerns the assessment of the occupational dust exposure. We constructed a population-specific JEM for dust exposure based on 29 job categories that were less detailed than the UCSF COPD Job Exposure Matrix. This may cause exposure 
misclassification. This bias can be viewed as non-differential misclassification since the exposure assessment was not related to outcome [Blair et al., 2007]. This misclassification might reduce statistical power and may bias the estimate toward the null, but would not affect the direction of the results (i.e., relation to outcome in the same direction) [Goldberg et al., 1993]. This may explain why we did not find a significant association between dust exposure and cross-sectional $\mathrm{FEV}_{1}$.

In addition, the actual dust exposure level may vary among people who have the same job categories but have different job tasks. We included "students" and "homemaker" in our analysis, i.e., viewed them as having an occupation; although they are not currently employed for salary they can be categorized as low exposure. Another limitation is that we did not exclude participants with pre-existing conditions such as COPD or asthma, due to a lack of such information. Future research that aims at finding the effect of dust exposure on lung function loss in a population-based study will be improved by more detailed job classifications and by direct personal measurements on at least a representative sample of individual job categories.

\section{Acknowledgments}

The Framingham Heart Study is conducted and supported by the National Heart, Lung, and Blood Institute (NHLBI) in collaboration with Boston University (Contract No. N01-HC-25195). This manuscript was not prepared in collaboration with investigators of the Framingham Heart Study and does not necessarily reflect the opinions or views of the Framingham Heart Study, Boston University, or NHLBI. Funding for SHARe genotyping was provided by NHLBI Contract N02-HL-64278. Funding support for the Framingham Social Network datasets was provided by NIA grant P01 AG 031093. This study was funded by NIH (NIEHS) ES00002. The findings and conclusions in this report are those of the authors. We would like to acknowledge the comments of Edwin K. Silverman, MD, PhD from Harvard Medical School and research assistance of Zhaoxi Wang, PhD from Harvard School of Public Health.

\section{References}

Bakke PS, Baste V, Hanoa R, Gulsvik A. Prevalence of obstructive lung disease in a general population: Relation to occupational title and exposure to some airborne agents. Thorax. 1991; 46:863-870. [PubMed: 1792631]

Balmes J, Becklake M, Blanc P, Henneberger P, Kreiss K, Mapp C, Milton D, Schwartz D, Toren K, Viegi G. American Thoracic Society Statement: Occupational contribution to the burden of airway disease. Am J Respir Crit Care Med. 2003; 167:787-797. [PubMed: 12598220]

Becklake MR, Lalloo U. The 'healthy smoker': A phenomenon of health selection? Respiration. 1990; 57:137-144. [PubMed: 2274712]

Blair A, Stewart P, Lubin JH, Forastiere F. Methodological issues regarding confounding and exposure misclassification in epidemiological studies of occupational exposures. Am J Ind Med. 2007; 50:199-207. [PubMed: 17096363]

Blanc PD, Iribarren C, Trupin L, Earnest G, Katz PP, Balmes J, Sidney S, Eisner MD. Occupational exposures and the risk of COPD: Dusty trades revisited. Thorax. 2009; 64:6-612. [PubMed: 18678700]

Buist AS, Vollmer WM, McBurnie MA. Worldwide burden of COPD in high- and low-income countries. Part I. The burden of obstructive lung disease (BOLD) initiative. Int J Tuberc Lung Dis. 2008; 12:703-708. [PubMed: 18544191]

Eisen EA, Wegman DH, Louis TA, Smith TJ, Peters JM. Healthy worker effect in a longitudinal study of one-second forced expiratory volume (FEV1) and chronic exposure to granite dust. Int J Epidemiol. 1995; 24:1154-1161. [PubMed: 8824857] 
Goldberg M, Kromhout H, Guenel P, Fletcher AC, Gerin M, Glass DC, Heederik D, Kauppinen T, Ponti A. Job exposure matrices in industry. Int J Epidemiol. 1993; 22(Suppl 2):S10-15. [PubMed: 8132382]

Heederik D, Kromhout H, Kromhout D, Burema J, Biersteker K. Relations between occupation, smoking, lung function, and incidence and mortality of chronic non-specific lung disease: The Zutphen study. Br J Ind Med. 1992; 49:299-308. [PubMed: 1599867]

Higgins IT. The epidemiology of chronic respiratory disease. Prev Med. 1973; 2:14-33. [PubMed: 4610551]

Hnizdo E, Yan T, Hakobyan A, Enright P, Beeckman-Wagner LA, Hankinson J, Fleming J, Lee Petsonk E. Spirometry longitudinal data analysis software (SPIROLA) for analysis of spirometry data in workplace prevention or COPD treatment. Open Med Inform J. 2010; 4:94-102. [PubMed: 20835361]

Jacobsen G, Schlunssen V, Schaumburg I, Taudorf E, Sigsgaard T. Longitudinal lung function decline and wood dust exposure in the furniture industry. Eur Respir J. 2008; 31:334-342. [PubMed: 17989115]

Johnsen HL, Hetland SM, Benth JS, Kongerud J, Soyseth V. Dust exposure assessed by a job exposure matrix is associated with increased annual decline in FE V1: A 5-year prospective study of employees in Norwegian smelters. Am J Respir Crit Care Med. 2010; 181:1234-1240. [PubMed: 20203247]

Johnsen HL, Kongerud J, Hetland SM, Benth JS, Soyseth V. Decreased lung function among employees at Norwegian smelters. Am J Ind Med. 2008; 51:296-306. [PubMed: 18213638]

Kanwal R, Kullman G, Fedan KB, Kreiss K. Occupational lung disease risk and exposure to butterflavoring chemicals after implementation of controls at a microwave popcorn plant. Public Health Rep. 2011; 126:480-494. [PubMed: 21800743]

Kauffmann F, Drouet D, Lellouch J, Brille D. Occupational exposure and 12-year spirometric changes among Paris area workers. Br J Ind Med. 1982; 39:221-232. [PubMed: 7093148]

Kerstjens HA, Rijcken B, Schouten JP, Postma DS. Decline of FEV1 by age and smoking status: Facts, figures, and fallacies. Thorax. 1997; 52:820-827. [PubMed: 9371217]

Korn RJ, Dockery DW, Speizer FE, Ware JH, Ferris BG Jr. Occupational exposures and chronic respiratory symptoms. A population-based study. Am Rev Respir Dis. 1987; 136:298-304. [PubMed: 3497594]

Kreiss K, Fedan KB, Nasrullah M, Kim TJ, Materna BL, Prudhomme JC, Enright PL. Longitudinal lung function declines among California flavoring manufacturing workers. Am J Ind Med. 2011; 55:657-668. [PubMed: 21932425]

Krzyzanowski M, Kauffmann F. The relation of respiratory symptoms and ventilatory function to moderate occupational exposure in a general population. Results from the French PAARC study of 16,000 adults. Int J Epidemiol. 1988; 17:397-406. [PubMed: 3403137]

Li CY, Sung FC. A review of the healthy worker effect in occupational epidemiology. Occup Med (Lond). 1999; 49:225-229. [PubMed: 10474913]

Liao SY, Lin X, Christiani DC. Gene-environment interaction effects on lung function- a genome-wide association study within the Framingham heart study. Environ Health. 2013; 12:101. [PubMed: 24289273]

MacNee W, Tuder RM. New paradigms in the pathogenesis of chronic obstructive pulmonary disease I. Proc Am Thorac Soc. 2009; 6:527-531. [PubMed: 19741262]

Monson, R., editor. Occupational Epidemiology. Boca Raton: CRC Press; 1990.

Omland O, Wurtz ET, Aasen TB, Blanc P, Brisman JB, Miller MR, Pedersen OF, Schlunssen V, Sigsgaard T, Ulrik CS, Viskum S. Occupational chronic obstructive pulmonary disease: A systematic literature review. Scand J Work Environ Health. 2014; 40:19-35. [PubMed: 24220056]

Oxman AD, Muir DC, Shannon HS, Stock SR, Hnizdo E, Lange HJ. Occupational dust exposure and chronic obstructive pulmonary disease. A systematic overview of the evidence. Am Rev Respir Dis. 1993; 148:38-48. [PubMed: 8317812]

Petran M, Cocarla A, Baiescu M. Association between bronchial hyper-reactivity and exposure to silicon carbide. Occup Med (Lond). 2000; 50:103-106. [PubMed: 10829429] 
Thaon I, Demange V, Herin F, Touranchet A, Paris C. Increased lung function decline in blue-collar workers exposed to welding fumes. Chest. 2012

Viegi G, Prediletto R, Paoletti P, Carrozzi L, Di Pede F, Vellutini M, Di Pede C, Giuntini C, Lebowitz MD. Respiratory effects of occupational exposure in a general population sample in north Italy. Am Rev Respir Dis. 1991; 143:510-515. [PubMed: 2001059]

Wang ML, Avashia BH, Petsonk EL. Interpreting periodic lung function tests in individuals: the relationship between 1- to 5-year and long-term FEV1 changes. Chest. 2006; 130:493-499. [PubMed: 16899850]

Wang ML, Petsonk EL. Repeated measures of FEV1 over six to twelve months: What change is abnormal? J Occup Environ Med. 2004; 46:591-595. [PubMed: 15213522]

Zock JP, Sunyer J, Kogevinas M, Kromhout H, Burney P, Anto JM. Occupation, chronic bronchitis, and lung function in young adults. An international study. Am J Respir Crit Care Med. 2001; 163:1572-1577. [PubMed: 11401876] 


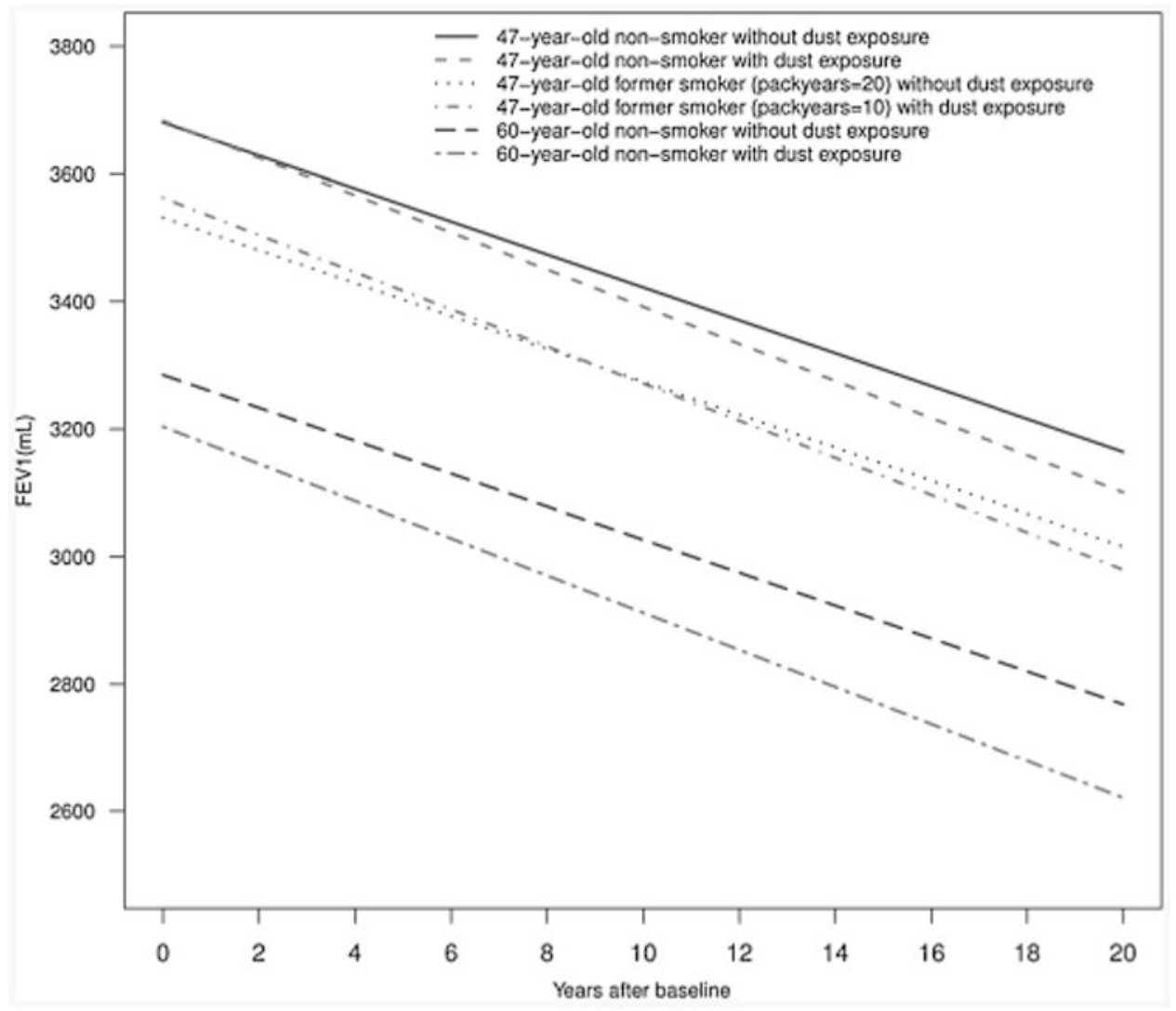

Figure 1.

Annual $\mathrm{FEV}_{1}$ loss for a male of 67-inch height in different dust exposure groups, different smoking status, baseline age, and pack-years based on the linear mixed model. 


\section{Table I \\ Job Categories for Dust Exposure Classification}

\begin{tabular}{ll} 
Dust exposure groups & Job categories \\
\hline More likely dust exposure & Factory/assembly/mechanic \\
& Skilled labor (e.g., plumber, carpenter, painter, hairdresser) \\
& General labor (e.g., custodian, delivery, mailman, truck driver) \\
& Heavy labor (e.g., construction, landscaping) \\
Less likely dust exposure & Nurse/medical personnel/laboratory technician \\
& Physical/occupational/speech therapist \\
& Homemaker \\
& Self-employed business owner \\
& Physician/dentist/scientist/research \\
& Lawyer/judge \\
& Psychologist/social worker/mental health counselor \\
& Engineer/computer science \\
& banker/accountant \\
& Manager/consultant (e.g., production manager) \\
& Administrative (e.g., personnel) \\
& Educator \\
& Secretary/clerk/data entry \\
Retail/cashier & Sales/marketing/insurance \\
& Realtor \\
& Police/fire/security/military \\
& Restaurant/food worker \\
& Writer/editor \\
& Artist/graphic Designer/craftsperson \\
& Musician \\
& Clergy (minister, priest, rabbi) \\
& Sports pro/coach/exercise instructor/other \\
& \\
\hline &
\end{tabular}


Table II

Characteristics of Participants at the Baseline Examination, Stratified by Dust Exposure Groups Classified at the Final Examination

Total ( $n=1332) \quad$ More likely dust exposure $(n=144) \quad$ Less likely dust exposure $(n=1188)$

\begin{tabular}{|c|c|c|c|}
\hline Male, n (\%) & $570(42.79)$ & $118(81.94)$ & $452(38.05)$ \\
\hline $\mathrm{FEV}_{1}, \mathrm{~mL}(\mathrm{SD})$ & $3130(820)$ & $3520(820)$ & $3080(800)$ \\
\hline $\mathrm{FEV}_{1} / \mathrm{FVC},(\mathrm{SD})$ & $0.77(0.07)$ & $0.76(0.08)$ & $0.77(0.07)$ \\
\hline Follow-up time, years (SD) & $16.88(5.44)$ & $17.25(4.36)$ & $16.96(4.53)$ \\
\hline Age, years (SD) & $47.44(10.55)$ & $45.89(11.15)$ & $47.63(10.47)$ \\
\hline Height, inches (SD) & $66.30(3.72)$ & $68.10(3.32)$ & $66.08(3.71)$ \\
\hline Pack-years*, (SD) & $21.35(19.80)$ & $27.80(21.24)$ & $20.30(19.38)$ \\
\hline \multicolumn{4}{|l|}{ Smoking status, n (\%) } \\
\hline Never smokers & $583(43.77)$ & $40(27.78)$ & $543(45.71)$ \\
\hline Former smokers & $429(32.21)$ & $52(36.11)$ & $377(31.73)$ \\
\hline Current smokers & $320(24.02)$ & $52(36.11)$ & $268(22.56)$ \\
\hline \multicolumn{4}{|l|}{ Genotyping, n (\%) } \\
\hline \multicolumn{4}{|l|}{ rs $9931086^{* *}$} \\
\hline $\mathrm{AC} / \mathrm{CC}$ genotypes & $370(27.78)$ & $32(22.22)$ & $338(28.45)$ \\
\hline AA genotype & $733(55.03)$ & $80(55.56)$ & $653(54.97)$ \\
\hline \multicolumn{4}{|l|}{$\operatorname{rs} 17051547^{* *}$} \\
\hline AC/AA genotypes & $239(17.94)$ & $20(13.89)$ & $219(18.43)$ \\
\hline CC genotypes & $990(74.32)$ & $111(84.09)$ & 879 (73.99) \\
\hline
\end{tabular}

FEV $_{1}$ : Forced expiratory volume in one second; FVC: Forced vital capacity; SD: Standard deviation; rs: Reference single nucleotide polymorphism number.

Values reported as means unless otherwise noted.

* Pack-years mean and standard deviation calculated among current and former smokers.

**

Not all participants had genotyping. 


\section{Table III \\ Characteristics Affecting $\mathrm{FEV}_{1}$ and $\mathrm{FEV}_{1} / \mathrm{FVC}$ by Linear Mixed Model}

\begin{tabular}{|c|c|c|c|c|}
\hline \multirow[b]{2}{*}{ Covariate } & \multicolumn{2}{|c|}{$\operatorname{FEV}_{1}(\mathbf{m L})$} & \multicolumn{2}{|c|}{$\mathrm{FEV}_{1} / \mathrm{FVC}$} \\
\hline & Estimate (SE) & $P$ value & Estimate (SE) & $P$ value \\
\hline \multicolumn{5}{|l|}{ Time-independent } \\
\hline More likely vs. less likely dust exposure & $-15.1(41.6)$ & 0.7173 & $-0.0039(0.0058)$ & 0.5030 \\
\hline Male vs. female & $712.6(34.1)$ & $<0.0001$ & $-0.0128(0.0048)$ & 0.0083 \\
\hline Baseline Age ${ }^{*}$ & $-30.6(1.3)$ & $<0.0001$ & $-0.0027(0.0002)$ & $<0.0001$ \\
\hline \multicolumn{5}{|l|}{ Time-dependent } \\
\hline Years after Baseline & $-25.8(0.6)$ & $<0.0001$ & $-0.0029(0.0001)$ & $<0.0001$ \\
\hline Current vs. never smoker & $-135.9(22.4)$ & $<0.0001$ & $-0.0175(0.0036)$ & $<0.0001$ \\
\hline Former vs. never smoker & $-92.8(19.6)$ & $<0.0001$ & $-0.0125(0.0031)$ & $<0.0001$ \\
\hline Pack-years & $-2.8(0.4)$ & $<0.0001$ & $-0.0004(0.0000)$ & $<0.0001$ \\
\hline Height & $61.5(4.2)$ & $<0.0001$ & $-0.0036(0.0006)$ & $<0.0001$ \\
\hline \multicolumn{5}{|l|}{ Interaction terms } \\
\hline Baseline age ${ }^{*} \times$ More likely dust exposure & $-7.1(3.7)$ & 0.0573 & $0.0001(0.0005)$ & 0.8907 \\
\hline Years after baseline agexMore likely dust exposure & $-4.5(1.7)$ & 0.0074 & $-0.0001(0.0003)$ & 0.6643 \\
\hline
\end{tabular}

$\mathrm{FEV}_{1}$ : Forced expiratory volume in one second; FVC: Forced vital capacity; SD: Standard deviation.

* Baseline age was centered on mean baseline age (47.44 years old). 